\title{
Acceptance Factors for Cryptocurrencies as Payment Systems
}

\author{
Peter Hamm \\ Goethe University Frankfurt \\ peter.hamm@m-chair.de
}

\begin{abstract}
The adoption of cryptocurrencies and blockchain technologies is an active field of research in information systems, looking at the promise and issues hampering the arrival of cryptocurrencies as a general means of payment. However, an overwhelming number of papers only look at existing users and usually limit themselves to a single cryptocurrency, mostly Bitcoin. This paper adds to the body of research by creating a taxonomy of features for cryptocurrencies as payment systems, and conducting a user study with over 500 participants asking what features are most relevant for the adoption of a cryptocurrency. We identify cost-effectiveness and data confidentiality as crucial for potential users, but also find that these two factors are followed by a wealth of convenience features that have found less emphasis in present cryptocurrency implementations.
\end{abstract}

\section{Introduction}

Since first appearing in 2009 [1], cryptocurrencies such as Bitcoin have experienced a meteoric rise in valuations and public attention. This has been accompanied by predictions that they could herald a revolution in the financial industry by shifting powers away from intermediaries such as banks towards individuals. However, the predicted changes failed to materialize, and the adoption of cryptocurrencies for retail clients did not take off in the same way their market capitalizations did [2]. This suggests that growth of cryptocurrencies is driven by factors other than adoption for everyday payments, with research pointing to Bitcoin being heavily used as an investment vehicle or for illicit payments [3]-[5], with the Bank for International Settlements going as far as declaring that Bitcoin and other decentralized cryptocurrencies are not adequate means of everyday payments [6], [7]. Jonker [2] conducted a representative survey among online retailers in the Netherlands and found that there is significant interest on the part of retailers to adopt payments using bitcoin specifically, but this be held back by a lack of customer demand. Given that most cryptocurrencies including Bitcoin were developed as payment systems first and foremost, this raises the question as to why they failed to establish themselves as alternative ways for customers to pay for goods in everyday transactions, and which factors and characteristics of cryptocurrencies are crucial for adoption by individuals. Past literature in IS research considered either the adoption of bitcoin or single cryptocurrencies and explored influencing factors [2], [8], [9] without differentiating between the features of different cryptocurrencies, which may include significant factors that improve on users' willingness to use those currencies for payment purposes. In this paper, we aim to answer the research question of what specific characteristics of cryptocurrencies do individuals consider important for accepting cryptocurrencies as payment systems. The identification of features is done employing general morphological analysis (GMA), a method developed by Zwicky [10], as this method allows us to capture all potentially relevant facets of different cryptocurrencies, which we then evaluate with a user study.

\section{Theoretical background}

The advent of Bitcoin [1] and other cryptocurrencies has led to a wealth of research examining different facets of this new technology. They proved to be fertile ground for the application of established information systems (IS) models, an overview of which will be given in the following section.

\subsection{Cryptocurrency adoption}

The adoption of cryptocurrencies by end users has seen a significant amount of previous research in the area of IS. Abramova and Böhme employed a technology acceptance model (TAM) to study the perceived benefits and risks of adopting Bitcoin as an online payment system, and found that individuals have significant concerns regarding the use of Bitcoin due to the perception that Bitcoin carries significant financial risk through value fluctuations, operational risks such as 
stolen passwords, as well as legal and regulatory risks [11]. Another approach using the TAM was taken by Folkinshteyn and Lennon, who create TAM models from the perspective of developers on one hand and end users on the other hand, and further distinguish between Bitcoin as a digital currency and blockchain used as a technology [12]. Seeking to identify barriers to adoption for blockchain technology in general, Sadhya and Sadhya conducted an inductive content analysis, combing through a wealth of archival data ranging from academic articles to Quora and Reddit posts, to identify 16 barriers to adoption ranging from lack of knowledge, and privacy and security, to specific issues such as the possibility of a $51 \%$ attack and storage concerns [13]. Looking at non-users, Mattke et al. employ qualitative comparison analysis to identify reasons for resisting Bitcoin as a payment system [14]. They identify six primary resistance reasons in transition costs, uncertainty costs, loss aversions, sunk costs, anticipated regret, and decisional control, and found that across different types of resistant users, anticipated regret acted as a necessary condition for resistant behaviors. Further research on non-users was done by Esmaeilzadeh et al. who conducted email interviews with MBA and BBA students in the United States. The participants were shown informative videos about Bitcoin to ensure familiarity, and then asked to participate in open-ended interviews on the perceived key benefits and harms of Bitcoin. This allowed the authors to build a model based on the unified theory of acceptance and use of technology (UTAUT) [15], and extend that model employing perceived benefits of Bitcoin, perceived risks, social effects, structural provision, and personality traits by analyzing interview responses [16]. The authors followed this up with another confirmatory study using the previously developed model and employing a survey among 843 U.S.-based individuals. They were able to confirm their previous results, and showed that the driving factor for individual adoption was the investment opportunity, while regulatory issues stood out as the most important barrier [17]. Looking beyond Bitcoin, Kimmerl employed a qualitative explorative interview study to shed insight on the perceptions of end-users towards global stablecoins such as Facebook's Libra (now Diem), identifying seven factor groups consisting of user specific factors, satisfaction with current payment infrastructure, perceived fulfilment of general properties requirements on global stablecoins, perceived fulfilment of regulatory requirements on global stablecoins, perceived data protection, perceived transparency, and perceived trust. She found that the general properties requirements of stablecoins, such as perceived system reliability, wide acceptance and perceived sustainability, as well as the fulfilment of regulatory requirements had an immense impact on the interviewees trust towards stablecoin usage and their issuers.

\subsection{Morphological Analysis}

GMA is a method developed by Zwicky [10] to structure and analyze multi-dimensional, non-quantified problems [18]. It functions by identifying all possible relevant dimensions or parameters of a problem, and assigning a list of all possible values or manifestations to each. This then allows the creation of a morphological box for field by listing each dimension with each possible value against each other. Using this box, we can analyze and compare all reasonable permutations of features against one another.

The morphological approach has previously been employed in the context of cryptocurrencies for classifying blockchain tokens [19], for that of crypto assets, and [20] for blockchain technologies in general [21]. Oliveira et al. employed a design-science approach, conducting a literature review to build a morphological box for the classification of tokens in real-world blockchain projects, which they evaluated and refined via interviews with 16 token project representatives. They arrived at a token classification framework, with the parameters classified into purpose parameters, governance parameters, functional parameters, and technical parameters. This framework formed the basis for a decision tree to inform decisions on whether a system should make use of tokens, and if yes, which kind thereof [19]. Wieninger et al. employ the GMA approach to develop a taxonomy of blockchain technologies based on literature, distinguishing between features related to participation, applications, and technology [21]. Finally, Ankenbrand et al. provide an overview over existing taxonomies on cryptographic assets found both in academic literature as well as standardization activities, and build a new framework with the expressed goal to classify all existing assets, including those from traditional finance as well as cryptoassets. This leads to a viewpoint more based on economics, and a parameter space of claim structure, technology, underlying, consensus/validation mechanism, legal status, governance, information complexity, legal structure, information interface, total supply, issuance, redemption, transferability, and fungibility [20].

\section{Morphological table of cryptocurrency payment systems and questionnaire}

The morphological approach fits our research problem very well as we aim to enumerate the whole set of features and properties of cryptocurrencies that are 
relevant for their adoption as a payment system specifically. Our approach to creating this morphological field differs from previous realizations in that we focus on one specific use case, which leads us to consider additional factors that are only relevant specifically for payment systems, such as the number and spread payment acceptance points (i.e. whether the currency in question is accepted as payment for relevant goods and services). Similar to [20], we aim to incorporate similar technologies outside of cryptocurrencies, such as mobile payment solutions into our taxonomy. A valuable starting point for this is previous research conducted by Kreyer et al. [22] and Pousttchi et al. [23], [24] on mobile payments, who constructed a mobile payment taxonomy based on the morphological approach, and used the possible values of the parameters to create a questionnaire, which in return formed the basis of a large-scale user study to gauge the importance of specific features to a representative sample of the German population.

\subsection{Morphological table}

As we aim to look at cryptocurrencies and their properties as payment systems specifically, none of the previously created taxonomies fulfills our need to answer our research question. However, the categories in [24] offer a valuable starting point. That taxonomy divides characteristic into the classes costs, security, and convenience, with the possibility to add other categories for things such as payment amounts. We decided to include "transaction costs" as the sole characteristic for costs, as fixed costs do not really factor into cryptocurrency usage, and are only really discussed in the context of mining [25]. In the category security we consider "confidentiality" with the possible instances low, medium, or high, as well as "anonymity" with given or not given. Confidentiality has previously been identified as a critical issue for the adoption of other payment systems [26], and anonymity (or pseudonymity) is often correctly or incorrectly named as one of the key features of Bitcoin and other cryptocurrencies [27], [28]. In the category convenience, we consider "ease of use" and "learnability" with the instances easy and complicated, as both have previously been identified as key issues with the adoption of cryptocurrencies [29]-[32]. Further entries in this category are "transaction speed" with fast and slow, and "acceptance points" with the subcharacteristics "number" with instances low, medium, and high, and "spread" with national and international, mostly due to the possibility of legal restrictions [33] [36]. We further decided to add "payment amounts" to this category, with the instances micropayments and macropayments, where we drew the line at 20 euro cents based on previous literature [24]. Finally, we added two characteristics that look at potential operators of payment services, one on who is a possible operator of the whole system "payment service provider" (PSP) with the instances banks, financial service providers (such as credit card companies), specialized intermediaries, cryptocurrency exchanges, and central banks. The last criterion we identified was "receiver of customer data" for entities that may not operate the system itself, but still handle personal or financial data, with the same instances as for "payment service provider". The results are shown in Table 1.

Table 1 - Morphological table of cryptocurrency payment system features

\begin{tabular}{|c|c|c|c|}
\hline Characteristic & \multicolumn{3}{|c|}{ Instances } \\
\hline $\begin{array}{l}\text { Transaction } \\
\text { costs }\end{array}$ & None & Low & High \\
\hline $\begin{array}{l}\text { Confidentiality } \\
\text { of data }\end{array}$ & Low & Medium & High \\
\hline $\begin{array}{l}\text { Anonymity } \\
\text { participants }\end{array}$ & Given & \multicolumn{2}{|c|}{ Not given } \\
\hline Ease of use & Easy & \multicolumn{2}{|c|}{ Complicated } \\
\hline Learnability & Easy & \multicolumn{2}{|c|}{ Complicated } \\
\hline $\begin{array}{l}\text { Transaction } \\
\text { speed }\end{array}$ & Fast & \multicolumn{2}{|l|}{ Slow } \\
\hline $\begin{array}{l}\text { Acceptance } \\
\text { points (number) }\end{array}$ & Low & Medium & High \\
\hline $\begin{array}{l}\text { Acceptance } \\
\text { points (spread) }\end{array}$ & National & \multicolumn{2}{|c|}{ International } \\
\hline $\begin{array}{l}\text { Payment } \\
\text { amounts }\end{array}$ & $\begin{array}{l}\text { Micro- } \\
\text { payments }\end{array}$ & \multicolumn{2}{|c|}{ Macropayments } \\
\hline \multirow[t]{2}{*}{$\begin{array}{l}\text { Payment service } \\
\text { provider }\end{array}$} & Banks & $\begin{array}{l}\text { Financial } \\
\text { service } \\
\text { providers }\end{array}$ & $\begin{array}{l}\text { Special- } \\
\text { ized inter- } \\
\text { mediaries }\end{array}$ \\
\hline & $\begin{array}{l}\text { Crypto- } \\
\text { currency } \\
\text { exchanges }\end{array}$ & \multicolumn{2}{|c|}{ Central banks } \\
\hline \multirow[t]{2}{*}{$\begin{array}{l}\text { Receiver of } \\
\text { customer data }\end{array}$} & Banks & $\begin{array}{l}\text { Financial } \\
\text { service } \\
\text { providers }\end{array}$ & $\begin{array}{l}\text { Special- } \\
\text { ized inter- } \\
\text { mediaries }\end{array}$ \\
\hline & $\begin{array}{l}\text { Crypto- } \\
\text { currency } \\
\text { exchanges }\end{array}$ & \multicolumn{2}{|c|}{ Central banks } \\
\hline
\end{tabular}




\subsection{Questionnaire}

To gauge how important each of these factors is to respondents, we constructed a questionnaire asking for agreement on a 5-point Likert scale. For "acceptance points (spread)" we simply changed the question to "payments abroad are possible", as the instances of this category distinguish primarily between national and international acceptance points. For payment amounts, we ask how important respondents consider the ability to pay less than 20 euro cents, as we assume that higher amounts are generally considered a given. We only deviated from the five-point scale for the final two categories, where we only asked participants whether they would accept or not accept each of the listed actors either as a payment service provider or as a receiver of customer data. The actors were taken from the final two characteristics in Table 1, with the additional information that credit card companies are an example for financial service providers. The final questions are listed in Table 2.

\section{Table 2. Acceptance criteria}

\begin{tabular}{|c|c|}
\hline Category & Factor \\
\hline Costs & No or low costs \\
\hline \multirow[t]{2}{*}{ Security } & Confidentiality of data \\
\hline & Payment transaction is anonymous \\
\hline \multirow[t]{6}{*}{ Convenience } & Easy handling \\
\hline & $\begin{array}{l}\text { Fast processing of the payment } \\
\text { transaction }\end{array}$ \\
\hline & High number of accepting merchants \\
\hline & $\begin{array}{l}\text { Easy learnability of the payment } \\
\text { procedure }\end{array}$ \\
\hline & Payment abroad possible \\
\hline & Payment of amounts $<20$ ct possible \\
\hline \multirow{5}{*}{\begin{tabular}{|l} 
Payment \\
service \\
provider
\end{tabular}} & Banks \\
\hline & Financial service providers \\
\hline & Specialized intermediaries \\
\hline & Cryptocurrency exchanges \\
\hline & Central banks \\
\hline \multirow{5}{*}{$\begin{array}{l}\text { Receiver of } \\
\text { customer } \\
\text { data }\end{array}$} & Banks \\
\hline & Financial service providers \\
\hline & Specialized intermediaries \\
\hline & Cryptocurrency exchanges \\
\hline & Central banks \\
\hline
\end{tabular}

\section{User Study}

In order to evaluate which factors play an important role for existing and potential users of cryptocurrency payments, we conducted a user study with a professional market research institute in Germany. Respondents were discarded if quotas concerning age and genders were already fulfilled, leading to a sample of 1053 participants representative for the German population. Participants were asked up front if they have already made payments using cryptocurrencies such as Bitcoin or Ethereum, or if they were willing to do so. 49 respondents stated that they had previously used cryptocurrencies for payments, 496 were in principle willing to use cryptocurrencies in such a manner, while the other 508 participants stated that they would not pay with cryptocurrencies in any case. The 545 users who did not rule out using cryptocurrencies as a means of payment were then shown the questionnaire introduced in section 3.2. In this sample, we had 313 male and 230 female respondents plus 2 who picked "other", versus 547 to 503 to 3 for all respondents including those that were excluded for not being willing to pay with cryptocurrencies in any case, indicating a slightly higher willingness to pay with cryptocurrencies among male participants. For those that have already paid with cryptocurrencies, the numbers are 38 males to 11 females, although the sample size is most likely too small to interpret this as hard evidence. The average age for all respondents who would at least consider using cryptocurrencies was 40.9 years, with males slightly older on average with 41.6 years compared to 39.9 for females. Table 3 offers a summary of the descriptive statistics for the sample.

\section{Table 3. Descriptive statistics}

\begin{tabular}{|l|c|c|}
\hline & $\mathrm{N}$ & Percent \\
\hline Education & & \\
\hline $\begin{array}{l}\text { Without general school leaving } \\
\text { certificate }\end{array}$ & 2 & $0.37 \%$ \\
\hline Lower secondary education & 42 & $7.71 \%$ \\
\hline Secondary school & 133 & $24.40 \%$ \\
\hline University entrance qualification & 156 & $28.62 \%$ \\
\hline Bachelors' degree & 83 & $15.23 \%$ \\
\hline Masters' degree and equivalent & 121 & $22.20 \%$ \\
\hline PhD and higher & 6 & $1.10 \%$ \\
\hline No answer & 2 & $0.37 \%$ \\
\hline Age & 142 & $26.06 \%$ \\
\hline $18-29$ & 128 & $23.49 \%$ \\
\hline $30-39$ & 113 & $20.73 \%$ \\
\hline $40-49$ &
\end{tabular}




\begin{tabular}{|l|c|c|}
\hline $50-59$ & 96 & $17.61 \%$ \\
\hline 60 and older & 66 & $12.11 \%$ \\
\hline Gender & & \\
\hline Male & 313 & $57.43 \%$ \\
\hline Female & 230 & $42.20 \%$ \\
\hline Other & 2 & $0.37 \%$ \\
\hline Annual Household Income & & \\
\hline Less than $10.000 €$ & 47 & $8.62 \%$ \\
\hline $10.000 €$ to $19.999 €$ & 49 & $8.99 \%$ \\
\hline $20.000 €$ to $29.999 €$ & 42 & $7.71 \%$ \\
\hline $30.000 €$ to $39.999 €$ & 67 & $12.29 \%$ \\
\hline $40.000 €$ to $49.999 €$ & 55 & $10.09 \%$ \\
\hline $50.000 €$ to $59.999 €$ & 64 & $11.74 \%$ \\
\hline $60.000 €$ to $79.999 €$ & 88 & $16.15 \%$ \\
\hline $80.000 €$ to $99.999 €$ & 40 & $7.34 \%$ \\
\hline $100.000 €$ to $149.999 €$ & 31 & $5.69 \%$ \\
\hline more than $150.000 €$ & 10 & $1.83 \%$ \\
\hline No answer & 52 & $9.54 \%$ \\
\hline Total & $\mathbf{5 4 5}$ & $\mathbf{1 0 0 . 0 0 \%}$ \\
\hline
\end{tabular}

Table 5. Approval for security criteria

\begin{tabular}{|l|l|c|}
\hline Category & Factor & Approval \\
\hline Security & Confidentiality of data & $89.36 \%$ \\
\cline { 2 - 3 } & $\begin{array}{l}\text { Payment transaction is } \\
\text { anonymous }\end{array}$ & $70.28 \%$ \\
\hline
\end{tabular}

For convenience factors (Table 6), a large majority named "easy handling", "fast processing of the payment transaction", "high number of accepting merchants", and "easy learnability of the payment procedure" as crucial factors. The relative importance of "payment abroad possible" was slightly lower at $76 \%$, but this criterium is generally not problematic for cryptocurrencies except in certain legislatures. Finally, the ability to use payment amounts below 20ct was only mentioned by a third of respondents, by far the lowest among any potential features.

Table 6. Approval for convenience criteria

For questions using a 5-point Likert scale ranging from "very unimportant" to "very important", answers given as "important" and "very important" were treated as approval.

The result for the category costs is listed in Table 4, with it's one question receiving the largest approval amongst all criteria with $90.64 \%$, indicating that price concerns play a dominant role for individuals when deciding on whether to adopt cryptocurrencies as a payment system.

Table 4. Approval for cost criterion

\begin{tabular}{|l|l|c|}
\hline Category & Factor & Approval \\
\hline Costs & No or low costs & $90.64 \%$ \\
\hline
\end{tabular}

Among security criteria (Table 5), "confidentiality of data" scored almost at $90 \%$. Interestingly, "payment transaction is anonymous" was in turn only considered important by slightly more than $70 \%$ of respondents. Anonymity or pseudonymity are often seen as main advantages of cryptocurrency-based payment systems [27], but this may indicate that this factor is not among the most critical for adoption by retail clients, compared to confidential handling of their data.

\begin{tabular}{|l|l|c|}
\hline Category & Factor & Approval \\
\hline Convenience & Easy handling & $89.17 \%$ \\
\cline { 2 - 3 } & $\begin{array}{l}\text { Fast processing of the } \\
\text { payment transaction }\end{array}$ & $87.89 \%$ \\
\cline { 2 - 3 } & $\begin{array}{l}\text { High number of accepting } \\
\text { merchants }\end{array}$ & $85.50 \%$ \\
\cline { 2 - 3 } & $\begin{array}{l}\text { Easy learnability of the } \\
\text { payment procedure }\end{array}$ & $82.57 \%$ \\
\cline { 2 - 3 } & Payment abroad possible & $76.33 \%$ \\
\cline { 2 - 3 } & $\begin{array}{l}\text { Payment of amounts }< \\
\text { 20ct possible }\end{array}$ & $33.39 \%$ \\
\hline
\end{tabular}

Finally, we consider payment service provider and receiver of customer data, the results for which are given in Table 7. In the former category, by far the most respondents announced that they are fine with banks as the operators of the payment system in question, who found approval by more than two thirds of respondents. This is followed by central banks and financial service providers (such as credit card companies) at $43.49 \%$ and $36.15 \%$, respectively. Cryptocurrency exchanges, which most likely are facilitating the highest number of cryptocurrency payments among all of the listed actors at the moment, and are the largest cryptocurrencyrelated industry by number of entities and headcount [37], only follow at fourth place with $28.26 \%$, while specialized intermediaries land at last place with $15.6 \%$. The same ordering holds when participants are asked which actors they would entrust their personal and financial data with, where again banks lead by far with 
more than $70 \%$ approval, followed by central banks with more than $41 \%$, financial service providers at almost a third of respondents, and then cryptocurrency exchanges at $19 \%$ and specialized intermediaries at $14 \%$, trailing the other actors by far.

Table 7. Approval for payment system providers and receivers of customer data

\begin{tabular}{|c|c|c|}
\hline Category & Factor & Approval \\
\hline \multirow{5}{*}{$\begin{array}{l}\text { Payment } \\
\text { service } \\
\text { provider }\end{array}$} & Banks & $68.62 \%$ \\
\hline & $\begin{array}{l}\text { Financial service } \\
\text { providers }\end{array}$ & $36.15 \%$ \\
\hline & $\begin{array}{l}\text { Specialized } \\
\text { intermediaries }\end{array}$ & $15.60 \%$ \\
\hline & $\begin{array}{l}\text { Cryptocurrency } \\
\text { exchanges }\end{array}$ & $28.26 \%$ \\
\hline & Central banks & $43.49 \%$ \\
\hline \multirow{5}{*}{$\begin{array}{l}\text { Receiver of } \\
\text { customer } \\
\text { data }\end{array}$} & Banks & $70.28 \%$ \\
\hline & $\begin{array}{l}\text { Financial service } \\
\text { providers }\end{array}$ & $32.66 \%$ \\
\hline & $\begin{array}{l}\text { Specialized } \\
\text { intermediaries }\end{array}$ & $14.13 \%$ \\
\hline & $\begin{array}{l}\text { Cryptocurrency } \\
\text { exchanges }\end{array}$ & $19.08 \%$ \\
\hline & Central banks & $41.65 \%$ \\
\hline
\end{tabular}

\section{Discussion}

Our user study pointed to a number of features potential users of cryptocurrency-based payment systems consider important, which we will discuss in turn.

Costs and confidentiality are potential dealbreakers

Low costs and data confidentiality are the features with the highest absolute approval rating, at $90.64 \%$ and $89.36 \%$ respectively. This by itself is not far from the next features such as easy handling. However, if we consider the proportion of people who considered these features "very important", the distance grows massively. $62.75 \%$ of respondents consider data confidentiality very important, and $60.73 \%$ do so for low costs. This is significantly more than for the next feature, which is easy handling at $52.29 \%$. This indicates that the lack of these two features specifically can be a deal-breaker for a significant proportion of potential users of cryptocurrency. This is consistent with past research on cryptocurrency adoption, as well as with the results on mobile payments by Pousttchi [24].

\section{Convenience matters}

After low costs and data confidentiality, the respondents expressed the largest amount of agreement towards a number of convenience factors, namely easy handling, fast processing, high number of accepting merchants, and easy learnability. This points to a pressing issue, as past research has shown that users' perceptions of the usability of specifically Bitcoin compared to credit cards is rather poor [38]. Transaction speed varies between cryptocurrencies, with block times ranging from 10 minutes for Bitcoin [39] to 15 seconds for Ethereum [40], although there exist expansions that enable faster transactions for a number of cryptocurrencies, such as the Lightning Network for Bitcoin [41]. The degree to which potential user perceptions of transaction speed are aligned with the actual figures is another topic that may warrant further consideration, although current research points to a significant portion of users perceiving Bitcoin to have fast transaction speeds [42]. The number of accepting merchants is another interesting conundrum, as previous research points to a low number of acceptance points being caused by lack of customer demand [2], [43], creating a chicken-egg problem that has to be overcome for cryptocurrency-based payments to reach a wider adoption. Learnability is another active topic of research, with accessibility to appropriate introductory information having been identified as a key issue [32]. No other approval factors achieved values higher than $80 \%$, the next ones being "payment abroad possible" at roughly $75 \%$ approval, "payment transaction is anonymous" at around 70\% approval, and finally with some distance "payment of amounts $<20$ ct possible" at $33.39 \%$

\section{Users look to banks as operators}

Looking at the potential actors in a payment system incorporating cryptocurrencies, respondents seemed to be at ease with commercial banks operating the system and handling their personal data, with $68.62 \%$ of respondents accepting banks as payment service providers and $70.28 \%$ willing to entrust banks with their personal and financial data. This is notable as the lack of a need for a central intermediary and specifically banks is often cited as a key advantage of cryptocurrencies, including in the original Bitcoin whitepaper by Nakamoto [1], [44]. The picture looks different for users who already have used cryptocurrencies, with only $42.86 \%$ accepting banks as payment system providers and $51.02 \%$ accepting them as handlers of personal and financial data, although it should be repeated that this sample was a small minority of the overall respondents with just 49 instances. The picture flips when regarding cryptocurrency exchanges, which currently form the main gateway to cryptocurrencies for most individuals [37], as $59.18 \%$ of 
actual cryptocurrency users approve of exchanges as payment system providers and $46.94 \%$ would entrust them with their financial and personal data, compared to $28.26 \%$ and $19.08 \%$ for the total sample. In terms of approval for the other actors, the subgroups had otherwise similar views. Actual cryptocurrency users showed a similar degree of approval for central banks to operate the payment system and handle their money at roughly $40 \%$, same for financial service providers. Agreement for specialized intermediaries to operate the system was at $22 \%$, slightly higher than the approval by the other group at $15 \%$. Otherwise, the subsamples agreed with regards to actors.

Overall, we receive a picture that shows customers are looking for low costs and confidentiality first and foremost. Both factors received roughly $90 \%$ approval as being important or very important, and $60 \%$ as very important specifically. This is ahead of the next factors of easy handling, fast processing, and high number of accepting merchants, which received between $89 \%$ and $85 \%$ approval as important or very important, but only $50 \%$ approval as very important, a notable gap of almost $10 \%$. This indicates that confidentiality and costs seem to be deal-breakers for a significant portion of potential users of cryptocurrencies as payment systems. Once these are fulfilled, customers seem to look for convenience functionality, as the next four factors are all in this category.

\section{Limitations and future research}

This study pointed to features potential users of cryptocurrencies may look for when intending to use them as a payment system. It aimed to capture a wider net of participants than usual by including individuals who do not have used cryptocurrencies in such a way yet. However, the results may still be biased due to the participants all coming from one country (Germany). Future studies may include more national backgrounds to better control for potential cultural differences. Due to focusing on the payment over the investment dimension of cryptocurrencies, we excluded value fluctuations as well as liquidity concerns other than "high number of accepting merchants" from our factors, although it may be argued that these things are still at the back of the mind of consumers. Another factor we did not consider was resiliency to hacking, either on the technical level or through bank guarantees. This is often assumed as given for classical research on the adoption of payment systems in the literature that we refer to ([22]-[24]), but may not be taken for granted for all cryptocurrencies. It is reasonable to assume this to be of critical importance, even more so than confidentiality as breaches of security can lead to the exposure of confidential information. Further research can look into the role perceived security plays in adoption decisions. The employed questionnaire further only asked for agreement on a scale and never required participants to name the most important factors, which may have missed features that a lower number of respondents consider very important. Our findings can only identify features that a high number of respondents name as important, but we do not develop further theories exploring the potential causal relationship between these features and intended and actual adoption of cryptocurrencies as payment systems. This also means we cannot identify how individuals perceive trade-offs, such as between cost effectiveness, ease of use and confidentiality. Future research should take a deeper look at the areas identified as important to potential users, and develop a theoretical framework explaining their relative importance and interrelations.

Based on our results, the future of cryptocurrency payments lies in payment systems that greatly enhance user convenience without compromising costs and data confidentiality. More research is needed to explain the reasoning users apply to consider these features as important, and to what extent these features or combinations of features are feasible to implement in practice.

\section{References}

[1] S. Nakamoto, "Bitcoin: A peer-to-peer electronic cash system," 2008.

[2] N. Jonker, "What drives the adoption of cryptopayments by online retailers?," Electron. Commer. Res. Appl., vol. 35, p. 100848, 2019.

[3] J. Bohr and M. Bashir, "Who uses bitcoin? an exploration of the bitcoin community," in 2014 Twelfth Annual International Conference on Privacy, Security and Trust, 2014, pp. 94-101. [4] F. Glaser, K. Zimmermann, M. Haferkorn, M. C. Weber, and M. Siering, "Bitcoin-asset or currency? revealing users' hidden intentions," Reveal. Users' Hidden Intentions (April 15, 2014). ECIS, 2014.

[5] H. S. Yin and R. Vatrapu, "A first estimation of the proportion of cybercriminal entities in the bitcoin ecosystem using supervised machine learning," in 2017 IEEE International Conference on Big Data (Big Data), 2017, pp. 3690-3699.

[6] Bank for International Settlements, "Cryptocurrencies: looking beyond the hype," Jun. 2018.

[7] H. Jones and D. Milliken, "BIS official casts doubt on El Salvador bitcoin 'experiment,"” Reuters, 2021.

[8] H. Albayati, S. K. Kim, and J. J. Rho, “Accepting financial transactions using blockchain technology and cryptocurrency: A customer perspective approach," Technol. Soc., vol. 62, p. 101320, 2020.

[9] H. Treiblmaier, D. Leung, A. O. J. Kwok, and A. Tham, "Cryptocurrency adoption in travel and tourism-an exploratory study of Asia Pacific 
travellers," Curr. Issues Tour.,pp. 1-17, 2020.

[10] F. Zwicky, "The morphological approach to discovery, invention, research and construction," in New methods of thought and procedure, Springer, 1967, pp. 273-297.

[11] S. Abramova and R. Böhme, "Perceived benefit and risk as multidimensional determinants of bitcoin use: A quantitative exploratory study," 2016 Int. Conf. Inf. Syst. ICIS 2016, pp. 1-20, 2016.

[12] D. Folkinshteyn and M. Lennon, "Braving Bitcoin: A technology acceptance model (TAM) analysis," $J$. Inf. Technol. Case Appl. Res., vol. 18, no. 4, pp. 220-249, 2016.

[13] V. Sadhya and H. Sadhya, "Barriers to Adoption of Blockchain Technology," Proc. 24th Am. Conf. Inf. Syst., pp. 1-10, 2018.

[14] J. Mattke, L. Müller, C. Maier, and T. Weitzel, "Bitcoin resistance behavior: A QCA study explaining why individuals resist bitcoin as a means of payment," Int. Conf. Inf. Syst. 2018, ICIS 2018, 2018.

[15] V. Venkatesh, M. G. Morris, G. B. Davis, and F. D. Davis, "User Acceptance of Information Technology: Toward a Unified View," MIS Q., vol. 27, no. 3, pp. 425-478, 2003.

[16] P. Esmaeilzadeh, H. Subramanian, and K. Cousins, 'Individuals' cryptocurrency adoption: A proposed moderated-mediation model," 25th Am. Conf. Inf. Syst. AMCIS 2019, no. Saito 2015, pp. 1-10, 2019.

[17] P. Esmaeilzadeh, K. Cousins, and H. Subramanian, "A Utility Theory Model for Individual Adoption of Bitcoin," in CONF-IRM 2020 Proceedings, 2020.

[18] A. Álvarez and T. Ritchey, "Applications of General Morphological Analysis," Acta Morphol. Gen., vol. 4, no. 1, pp. 1-40, 2015.

[19] L. Oliveira, I. Bauer, L. Zavolokina, and G. Schwabe, "To token or not to token: Tools for understanding blockchain tokens," Int. Conf. Inf. Syst. 2018, ICIS 2018, no. December, 2018.

[20] T. Ankenbrand, D. Bieri, R. Cortivo, J. Hoehener, and T. Hardjono, "Proposal for a Comprehensive (Crypto) Asset Taxonomy," Proc. - 2020 Crypto Val. Conf. Blockchain Technol. CVCBT 2020, pp. 16-26, 2020.

[21] S. Wieninger, G. Schuh, and V. Fischer, "Development of a Blockchain Taxonomy," Proc. 2019 IEEE Int. Conf. Eng. Technol. Innov. ICE/ITMC 2019, 2019.

[22] N. Kreyer, K. Pousttchi, and K. Turowski, "Standardized payment procedures as key enabling factor for mobile commerce," in International Conference on Electronic Commerce and Web Technologies, 2002, pp. 400-409.

[23] K. Pousttchi, B. Selk, and K. Turowski, "Akzeptanzkriterien für mobile Bezahlverfahren," 2002.

[24] K. Pousttchi, "Conditions for acceptance and usage of mobile payment procedures," 2003.

[25] R. Garratt and M. R. C. van Oordt, "Why Fixed Costs Matter for Proof-of-Work Based Cryptocurrencies," SSRN Electron. J., 2020.
[26] L. Da Chen, "A model of consumer acceptance of mobile payment," Int. J. Mob. Commun., vol. 6, no. 1, pp. 32-52, 2008.

[27] F. Reid and M. Harrigan, "An analysis of anonymity in the bitcoin system," Secur. Priv. Soc. Networks, pp. 197-223, 2013.

[28] A. Al Shehhi, M. Oudah, and Z. Aung, "Investigating factors behind choosing a cryptocurrency," IEEE Int. Conf. Ind. Eng. Eng. Manag., vol. 2015-Janua, pp. 1443-1447, 2014.

[29] O. Sohaib, W. Hussain, M. Asif, M. Ahmad, and M. Mazzara, "A PLS-SEM Neural Network Approach for Understanding Cryptocurrency Adoption," IEEE Access, vol. 8, pp. 13138-13150, 2020.

[30] R. Al-Amri, N. H. Zakaria, A. Habbal, and S. Hassan, "Cryptocurrency adoption: current stage, opportunities, and open challenges," Int. J. Adv. Comput. Res., vol. 9, no. 44, pp. 293-307, 2019.

[31] S. Abooleet and X. Fang, "A unified transaction cost model for adoption of payment technologies," 26th Am. Conf. Inf. Syst. AMCIS 2020, pp. 0-5, 2020.

[32] L. Glomann, M. Schmid, and N. Kitajewa, Improving the Blockchain User Experience - An Approach to Address Blockchain Mass Adoption Issues from a Human-Centred Perspective, vol. 965. Springer International Publishing, 2020.

[33] T. Slattery, Taking a Bit out of Crime: Bitcoin and Cross-Border Tax Evasion, vol. 39, no. 2. 2014.

[34] L. C. Schaupp and M. Festa, "Cryptocurrency adoption and the road to regulation," ACM Int. Conf. Proceeding Ser., pp. 1-9, 2018.

[35] M. Inshyn, L. Mohilevskyi, and O. Drozd, "the Issue of Cryptocurrency Legal Regulation in Ukraine and All Over the World: a Comparative Analysis," Balt. J. Econ. Stud., vol. 4, no. 1, pp. 169-174, 2018.

[36] H. Nabilou, "How to regulate bitcoin? Decentralized regulation for a decentralized cryptocurrency," Int. J. Law Inf. Technol., vol. 27, no. 3, pp. 266-291, 2019.

[37] G. Hileman and M. Rauchs, "Global cryptocurrency benchmarking study," Cambridge Cent. Altern. Financ., vol. 33, pp. 33-113, 2017.

[38] A. Al Shamsi and P. Andras, "User Perception of Bitcoin Usability and Security across Novice Users Abdulla AlShamsi and Peter Andras School of Computing and Mathematics Keele University," vol. 2019.

[39] Y. Kawase and S. Kasahara, "Transactionconfirmation time for bitcoin: A Queueing analytical approach to blockchain mechanism," Lect. Notes Comput. Sci. (including Subser. Lect. Notes Artif. Intell. Lect. Notes Bioinformatics), vol. 10591 LNCS, pp. 75-88, 2017.

[40] D. Vujičić, D. Jagodić, and S. Randić, "Blockchain technology, bitcoin, and Ethereum: A brief overview," 2018 17th Int. Symp. INFOTEHJAHORINA, INFOTEH 2018 - Proc., vol. 2018Janua, pp. 1-6, 2018.

[41] J. Poon and T. Dryja, "The bitcoin lightning network: Scalable off-chain instant payments." 2016. 
[42] H. M. Gazali, C. M. H. B. C. Ismail, and T. Amboala, "Exploring the intention to invest in cryptocurrency: The case of bitcoin," Proc. - Int. Conf. Inf. Commun. Technol. Muslim World 2018, ICT4M 2018, pp. 64-68, 2018.
[43] D. Yermack, "Is Bitcoin a Real Currency?," SSRN Electron. J., 2013.

[44] A. M. Antonopoulos, Mastering Bitcoin: unlocking digital cryptocurrencies. "O'Reilly Media, Inc.," 2014. 